\title{
Lo erótico como epistemología del Sur: perspectivas feministas desde Audre Lorde ${ }^{1}$
}

\author{
O erótico como epistemologia do Sul: \\ perspectivas feministas desde Audre Lorde \\ The erotic as epistemology of the South: \\ feminist perspectives from Audre Lorde
}

Antoni Aguiló

\begin{abstract}
Resumen
El objetivo principal de este trabajo es analizar el vínculo entre conocimiento, género y poder desde la perspectiva de la epistemología feminista de Audre Lorde. Lorde plantea una visión de lo erótico como una epistemología del Sur que constituye una fuente de empoderamiento, contrahegemonía y emancipación para los grupos sociales oprimidos, en particular para las mujeres negras lesbianas que sufren la violencia generada por sistemas de poder que continúan subyugando a las mujeres, como el patriarcado epistémico.
\end{abstract}

Palabras clave: epistemologías del Sul; feminismo; Audre Lorde; erotismo; descolonización.

\section{Resumo}

O objectivo principal deste trabalho é analisar a ligação entre conhecimento, género e poder na perspectiva da epistemologia feminista de Audre Lorde. Lorde propõe uma visão do erótico como uma epistemologia do Sul que constitui uma fonte de empoderamento, contra-hegemonia e emancipação para grupos sociais oprimidos, particularmente para as mulheres negras lésbicas que sofrem a violência gerada por sistemas de poder que continuam a subjugar as mulheres, como o patriarcado epistémico.

Palavras-chave: epistemologias do Sul; feminismo; Audre Lorde; erotismo; descolonização.

Abstract

\footnotetext{
${ }^{1}$ Artículo presentado en el I Congresso Internacional Online de Estudos sobre Culturas, modalidad virtual, 2019. Este artículo ha sido posible gracias al apoyo financiero de la Fundação para a Ciência e a Tecnologia (FCT) a través de su concurso público para la atribución de becas de posdoctorado (2014), que cuenta con un presupuesto compartido por fondos del Ministério da Ciência, Tecnologia e Ensino Superior de Portugal y el Fondo Social Europeo a través del Programa Operacional Capital Humano (POCH).

${ }^{2}$ Doctor en Humanidades y Ciencias Sociales, Centro de Estudos Sociais da Universidade de Coimbra, Coimbra (Portugal); antoniaguilo@ces.uc.pt.
} 
The main objective of this paper is to analyse the relation between knowledge, gender and power from the perspective of the feminist epistemology of Audre Lorde. Lorde poses a vision of the erotic as an epistemology of the South that constitutes a source of empowerment, counter-hegemony and emancipation for oppressed social groups, particularly for lesbian black women who suffer the violence generated by systems of power that continue to subjugate women, as the epistemic patriarchate.

Keywords: epistemologies of the South; feminism; Audre Lorde; eroticism; decolonisation.

\section{Introducción}

En unas declaraciones con motivo de la presentación de su libro Te amo, el sociólogo Francesco Alberoni aseguraba que "la sociedad considera obsceno mezclar ciencia y sentimiento". 3 Con sus palabras, Alberoni estaba desafiando ciertas lógicas epistémicas positivistas que aún hoy condicionan el conocimiento hegemónico que se produce, enseña y transmite en las instituciones educativas. Así, desde esta óptica, la universidad, tal y como la conocemos, puede considerarse un espacio elitista donde la construcción del saber no se inspira en la experiencia de sectores populares, sino en los intereses, las experiencias y los saberes de las clases y los grupos dominantes, de quienes históricamente han estado del lado de la opresión y la injusticia. Ya lo advertía en 1959 el Che Guevara en su discurso de investidura como doctor honoris causa por la Universidad Central de Las Villas, donde le pide a la universidad que

se pinte de negro, que se pinte de mulato, no solo entre los alumnos, sino también entre los profesores; que se pinte de obrero y de campesino, que se pinte de pueblo, porque la Universidad no es el patrimonio de nadie y pertenece al pueblo (GUEVARA, 2008, p. 284).

Una crítica radical y sistemática de estas lógicas como fuente estructural de poder y dominación es la que plantea Boaventura de Sousa Santos (2017, 2019a), quien explora las posibilidades de una alternativa epistemológica emancipadora respecto al predominio de las "epistemologías del Norte" y sus efectos. Las epistemologías del Norte se caracterizan, en términos generales, por la primacía del conocimiento científico inspirado en la racionalidad baconiana-cartesiana (simplificación, sistematización, verificación empírica, clasificación y compartimentación del saber); la importancia de la objetividad, equiparada con la neutralidad política y cognitiva que presumiblemente caracteriza al sujeto cognoscente; la importancia de la universalización de la teoría; una separación rígida entre el sujeto y el objeto de

3 Véase El País, edición del 16 de noviembre de 1996. Disponible en: https://elpais.com/diario/1996/11/16/cultura/848098805_850215.html (consulta: 27/1/2020). 
investigación; y una fuerte dicotomía entre teoría y práctica. El conocimiento legítimo es científico, racional, universal, imparcial y se produce aislado de la influencia de las emociones y las variables políticas contextuales.

En su libro El fin del imperio cognitivo, Santos (2019a) argumenta que las epistemologías del Norte son abisales, es decir, establecen una línea desde la cual se crea el apartheid del conocimiento entre este lado de la línea, donde se produce el conocimiento válido, y el otro lado, donde solo hay supersticiones, creencias u opiniones sin fundamento. De este modo, los conocimientos situados al otro lado de la línea abisal se vuelven ilegítimos e invisibles, se producen como inexistentes desde el punto de vista epistemológico. De hecho, las epistemologías del Norte funcionan como políticas de conocimiento, como formas de instituir lo que Michael Foucault (1994) llamó regímenes de verdad. En este sentido, se revelan como poderosos instrumentos al servicio de las que Santos (2017) considera las tres grandes formas de dominación moderna: el capitalismo, el colonialismo y el heteropatriarcado. Para la teoría decolonial latinoamericana (LANDER, 2000), el concepto de colonialidad $^{4}$ del saber alude precisamente a la supresión o subordinación jerárquica de las formas de comprensión del mundo, de producción de conocimiento y de expresión cultural propias de los legados históricos no occidentales, por considerarse inferiores, atrasadas, irracionales, etc.

Fue así como aprendimos a producir conocimientos que desde siglos vienen marginando la voz, los saberes, las experiencias y las necesidades de colectivos subalternos, como, entre otros, las mujeres, los colectivos LGTBI, los migrantes indocumentados, las personas en situación de discapacidad o las minorías étnicas; conocimientos que consagran la hegemonía del pensamiento discursivo basado en libros y clases magistrales frente a un conocimiento incapaz de incorporar lo afectivo, lo cotidiano y las experiencias de vida; conocimientos que bajo la coartada de la neutralidad rechazan cualquier toma de posición que

\footnotetext{
${ }^{4} \mathrm{El}$ concepto de colonialidad se refiere a un residuo sociohistórico del colonialismo formal que pervive en el imaginario social (QUIJANO, 2000; $\quad$ MIGNOLO, 2003; CASTRO-GÓMEZ, 2011). Para Ramón Grosfoguel, la colonialidad, más específicamente, remite a "un patrón de poder que se inaugura con la expansión colonial europea a partir de 1492 donde la idea de raza y la jerarquía etnorracial global atraviesa todas las relaciones sociales existentes tales como la sexualidad, género, conocimiento, clase, división internacional del trabajo, epistemología, espiritualidad, etc., y que sigue vigente aun cuando las administraciones coloniales fueron casi erradicadas del planeta" (apud MONTES y BUSSO, 2007). Santos (2006, p. 50) no asume esta distinción analítica y habla de colonialismo formal y de colonialismo, sin adjetivos, para referirse a las formas renovadas de colonialismo. Para él, colonialismo remite, en general, a "todos los trueques, los intercambios, las relaciones, donde una parte más débil es expropiada de su humanidad", o expresado en otros términos: "El colonialismo es la concepción que ve al otro como objeto, no como sujeto" (SANTOS, 2005, p. 106).
} 
huela a compromiso social; conocimientos que convierten a los sujetos en objetos para investigar sobre ellos, pero raramente con ellos.

A partir de estas premisas introductorias surgen algunas preguntas orientadoras que vale la pena formular: ¿es posible ir más allá de los códigos heredados castrantes de las epistemologías del Norte? ¿Cómo diseñar estrategias de investigación no normativas, abiertas a la diversidad? ¿Se puede abrir camino hacia gramáticas epistémicas alternativas capaces de rescatar y legitimar otras experiencias de conocimiento como los rituales, las emociones, las artes visuales, las historias orales, la danza y el rap? ¿Pueden los sentimientos formar parte legítima de la práctica epistemológica?

\section{Patriarcado epistémico vs epistemologías feministas del Sur}

Para responder a estos interrogantes es necesario, en primer lugar, generar las condiciones esenciales para superar la hegemonía global de las epistemologías del Norte. Santos $(2009,2019 b)$ ofrece la clave cuando afirma que para ello es un imperativo ineludible ir hacia el Sur para aprender del Sur y con el Sur, pero no del Sur imperial (que reproduce la lógica del Norte tomada como universal), sino del Sur antiimperialista, metáfora del sufrimiento humano sistemático e injusto causado por el capitalismo, el colonialismo y el patriarcado.

En este contexto es donde cabe situar las epistemologías del Sur que plantea Santos con la intención de superar el sistema abisal y eurocéntrico de conocimiento hegemónico. El objetivo es buscar alternativas capaces de promover el conocimiento de los grupos subalternos con el objetivo de descolonizar, despatriarcalizar y desmercantilizar la vida humana a partir de los conocimientos que nacen en las luchas y permiten que los grupos oprimidos "representen el mundo como suyo y en sus propios términos" (Santos, 2019a, p. 21). Así enfocadas, las epistemologías del Sur son un ejercicio de desobediencia y creatividad capaz de intensificar las luchas colectivas por la transformación social emancipadora. Formalmente se definen como un reclamo en clave posabisal de

nuevos procesos de producción y de valoración de conocimientos válidos, científicos y no científicos, y de nuevas relaciones entre diferentes tipos de conocimiento, a partir de las prácticas de las clases y grupos sociales que han sufrido de manera sistemática las injustas desigualdades y las discriminaciones causadas por el capitalismo y por el colonialismo (SANTOS, 2011, p. 35). 
A raíz de esta problemática, han surgido diversas corrientes, enfoques y análisis que buscan rescatar las trayectorias y contribuciones del Sur global a partir de las narrativas y las estrategias de acción y resistencia de mujeres invisibilizadas e inferiorizadas por las epistemologías del Norte, planteando así la estrecha conexión que puede establecerse entre el feminismo y las epistemologías del Sur (Mendoza, 2010). A este respecto, la antropóloga Mara Viveros Vigoya destaca que las epistemologías feministas del Sur

\begin{abstract}
abarcan una amplia gama de perspectivas que abogan por nuevas formas de producción y validación de los conocimientos feministas, académicos y no académicos, y nuevas relaciones entre formas de conocimiento. Se trata de escuchar las prácticas de los grupos sociales que más han sufrido las consecuencias del colonialismo y el capitalismo neoliberal (Santos, 2011). Las reflexiones y experiencias de una parte importante del feminismo latinoamericano hunden sus raíces en un Sur que representa menos un concepto geográfico que una metáfora de las luchas y la resistencia contra la opresión y la discriminación por motivos de género, clase, etnia, "raza" y sexualidad (VIVEROS VIGOYA, 2018, p. 91). ${ }^{5}$
\end{abstract}

Las epistemologías feministas del Sur denuncian y combaten la complicidad entre el patriarcado y las epistemologías del Norte. Se rebelan contra una tradición académica patriarcal que recluyó a las mujeres en el espacio considerado privado, las entregó al trabajo doméstico reproductivo y justificó diversas explotaciones, mientras que a los hombres les entregó el conocimiento científico, el espacio público, el trabajo productivo y les enseñó que las tareas intelectuales deben regirse por la objetividad y la neutralidad, que públicamente hay que reprimir ciertos sentimientos, que dos hombres solo pueden ser amigos y que las mujeres son seres vulnerables y dependientes del varón.

Como observa Enrique Leff, para hacer frente al saber patriarcal todavía dominante en los espacios académicos y educativos

\footnotetext{
necesitamos desconstruir toda la herencia del pensamiento metafísico y de la racionalidad de la modernidad; no solo sacrificar las palabras para renovar sus significados, para inventar nuevas semánticas y nuevas gramáticas; sino erotizar el saber para que más allá del conocimiento objetivo de la realidad, podamos acariciar y abrazar la vida, con dedos, manos, lenguas y brazos; para construir los puentes hacia un futuro sustentable, asumiendo nuestra condición humana y aprendiendo a vivir en los turbulentos mares de la vida; resistiendo la muerte entrópica del planeta y abriendo el camino hacia otros mundos posibles (LEFF, 2009, p. 22).
}

\footnotetext{
${ }^{5}$ La traducción es mía.
} 
En este sentido, acojo la propuesta de Leff de erotizar el saber, de recuperar lo erótico como energía humana creadora y emancipadora de la que pueden surgen nuevas y desafiantes posibilidades de conocimiento. Erotizar el saber con el objetivo de desarticular las epistemologías del Norte y el patriarcado epistémico que imponen, que descalifica el conocimiento producido por las mujeres, juzgadas como seres inferiores portadores de un conocimiento falso, subjetivo e irracional o, en su defecto, de ignorancia; que les niega el derecho a decidir sobre su propio cuerpo y que domestica su capacidad erótica, en el mejor de los casos reducida a una sexualidad que se realiza en el plano puramente genital. Como afirma Leff (2009, p. 22): "El erotismo de la vida abre los caminos al infinito, al por-venir, a lo que aún no es, atrapado por el exceso de racionalidad”.

Tomando como fuente de inspiración los trabajos de Ronald S. Laura (1999; 2018) sobre la llamada "epistemología del poder", por patriarcado epistémico se entiende aquí una estructura histórica de saber y poder cuya lógica se basa en el afán masculino de poder y control sobre las mujeres, cuyos cuerpos, saberes y experiencias son sistemáticamente negados, marginados, subordinados y expropiados en diferentes medidas e intensidades. Uso este término para referirme al enraizamiento social, cultural e institucional de una forma particular de conocimiento cuyo predominio a escala global le sirve como coartada para afirmar su autoproclamada superioridad con respecto a otras formas igualmente legítimas de conocer e interpretar el mundo. Esta perspectiva cognitiva supremacista justifica el patrón de poder eurocéntrico, masculino, heterosexual, capitalista y blanco imperante que degrada razas, etnias, cuerpos, saberes, sexualidades y géneros.

Una de las principales formas a través de las cuales el patriarcado epistémico ejerce control y opresión sobre la vida de las mujeres es mediante el establecimiento de dicotomías de oposición, como razón/emoción, cuerpo/alma y cultura/naturaleza, entre otras. Estas dicotomías condicionan la manera de representar y comprender el mundo, pues reproducen jerarquías y clasificaciones colonialistas que determinan el estado otorgado a algo o a alguien en particular. A medida que colectivos sociales como mujeres, homosexuales o comunidades indígenas son situados en el lado negativo de la jerarquía, no solo se les resta valor ontológico y epistemológico, sino que además se les otorga el estatuto de objetos disponibles para subyugar y explotar. Los valores consagrados por el patriarcado epistémico perpetúan, pues, una comprensión del mundo en la que los privilegios los poseen los hombres. ${ }^{6}$ Audre Lorde

\footnotetext{
${ }^{6}$ Es un error suponer que todos los hombres se benefician por igual del patriarcado epistémico, y de manera análoga que todas las mujeres son víctimas en la misma medida de él. Los varones homosexuales, por ejemplo,
} 
(2003: 16) lo expresa con lucidez cuando afirma: "Los padres blancos nos dijeron: «Pienso, luego existo». La madre negra que todas llevamos dentro, la poeta, nos susurra en nuestros sueños: «Siento, luego puedo ser libre»".

Ahora bien, la pregunta que se deriva inmediatamente de este planteamiento es si el conocimiento en sí mismo puede ser una práctica erotizable y si, en caso de serlo, qué significado tiene erotizar el saber desde las epistemologías feministas del Sur. Puesto que debe admitirse que no hay una única respuesta a esta última pregunta, abordaré a modo ilustrativo la propuesta de erotización del saber de la epistemología feminista de Audre Lorde. La tesis que defiendo es que lo erótico en Lorde funciona como una epistemología del Sur, como un pensar desde los oprimidos, desde aquellas dimensiones negadas o reprimidas del saber que buscan recuperar esas otras experiencias relacionadas con la corporeidad, la comunidad y la espiritualidad. Se trata de experiencias que permiten ampliar la comprensión del mundo frente a la limitada comprensión que proporciona la racionalidad patriarcal propia de las epistemologías del Norte.

De esta forma, se presentan las líneas generales de la concepción lordeana de lo erótico como fuerza política y vital capaz de colaborar activamente no solo en el desmantelamiento de las epistemologías del Norte, es decir, de contribuir a la descolonización y la despatriarcalización de los prejuicios, las jerarquías y discriminaciones inherentes al capitalismo, el colonialismo y el heteropatriarcado, sino también como fuerza creativa que apunta a un conocimiento rebelde y posabisal.

\section{El saber erótico en Audre Lorde}

En la obra Danzar su vida Roger Garaudy (2003) ofrece una clave fundamental para entender qué significa erotizar el saber cuando afirma que erotizar nuestra relación con el mundo significa recuperar las dimensiones del ser humano que se perdieron o debilitaron con el advenimiento de la modernidad eurocéntrica, como la dimensión comunitaria, la dimensión de misterio y la dimensión poética. Se trata, en pocas palabras, de reencontrarse con aquellos aspectos humanos olvidados que en otros términos de análisis Santos (2003, p. 82) llama las "representaciones inacabadas" de la modernidad occidental, como el principio de comunidad y la racionalidad estético-expresiva.

se enfrentan muy a menudo a lógicas de deshumanización, así como también existen mujeres cómplices de la subordinación patriarcal. 
Para Audre Lorde el erotismo constituye precisamente una de esas dimensiones abandonadas por la razón moderna dualista cartesiana y reducidas por el patriarcado a una "sensación confusa, trivial, psicótica y artificial" que se tergiversa como pornografía (LORDE, 2003, p. 38). Tal y como denuncia:

\footnotetext{
No es que le racionalidad no sea necesaria. Está al servicio del caos del conocimiento. Al servicio del sentimiento. Sirve para ir de un lugar a otro. Pero si no se concede valor a esos lugares, el camino no vale de nada. $\mathrm{Y}$ eso es lo que sucede muy a menudo con el culto a la racionalidad y con el pensamiento analítico, académico, circular (LORDE, 2003, p. 102).
}

Frente al racionalismo moderno y las jerarquías dualistas que justifican la opresión de un grupo por otro, Lorde evoca la idea de una razón erótica, de un conocimiento erótico, de una fuerza vital latente que nos conduce a la creación y a la belleza, y que nos permite reconectarnos con lo esencial de la vida:

La dicotomía entre lo espiritual y lo político es asimismo falsa, ya que deriva de una falta de atención a nuestro conocimiento erótico. Pues el puente que conecta lo espiritual y lo político es precisamente lo erótico, lo sensual, aquellas expresiones físicas, emocionales y psicológicas de lo más profundo, poderoso y rico de nuestro interior, aquello que compartimos: la pasión del amor en su sentido más profundo (LORDE, 2003, p. 41).

En virtud de ello, lo erótico es reconocido como una fuerza formada fundamentalmente por tres dimensiones complementarias. En primer lugar, como una potencia lúdica relacionada con el goce, el placer y la satisfacción física, intelectual y emocional:

Otra función importante de la conexión erótica es que hace resaltar con sinceridad y valentía mi capacidad de gozar. Así como mi cuerpo reacciona a la música relajándose y abriéndose a ella, atento a sus más profundos ritmos, todo aquello que siento me abre a la experiencia eróticamente satisfactoria, ya sea al bailar, al montar una estantería, al escribir un poema o al analizar una idea (LORDE, 2003, p. 42).

En segundo lugar, como una potencia crítica que alimenta el inconformismo, la rebeldía y alberga la posibilidad de insubordinación frente a la docilidad y la obediencia de las que se sirve la opresión: 


\begin{abstract}
Nuestro conocimiento erótico nos fortalece, se convierte en una lente a través de la cual escudriñamos todos los aspectos de nuestra existencia, lo que nos obliga a evaluarlos honestamente y a adjudicarles el valor relativo que poseen en el conjunto de la vida. Y obrar así es una gran responsabilidad que surge de nuestro interior: la responsabilidad de no conformamos con lo que es conveniente, falso, convencional o meramente seguro (LORDE, 2003, p. 42)
\end{abstract}

Por último, Lorde concibe lo erótico como una potencia o recurso creativo que "reside en el interior de todas nosotras, asentado en un plano profundamente femenino y espiritual, y firmemente enraizado en el poder de nuestros sentimientos inexpresados y aún por reconocer" (LORDE, 2003, p. 37). Y en la misma línea, añade: "Lo erótico es como una semilla que llevo dentro. Cuando se derrama fuera de la cápsula que lo mantiene comprimido, fluye y colorea mi vida con una energía que intensifica, sensibiliza y fortalece toda mi experiencia” (LORDE, 2003, p. 43). Así, solo a partir del reconocimiento de lo erótico como fuente legítima de poder estamos en condiciones de atravesar la línea abisal, de adoptar un posicionamiento ético y político que nos permita observar y reconocer las intervenciones coloniales en nuestras vidas: "Para mí lo erótico es una afirmación de la fuerza vital de las mujeres; de esa energía creativa y fortalecida, cuyo conocimiento y uso estamos reclamando ahora en nuestro lenguaje, nuestra historia, nuestra danza, nuestro amor, nuestro trabajo y nuestras vidas" (LORDE, 2003, p. 40).

Como potencia creativa, lo erótico propicia encuentros intersubjetivos y refuerza una red de vínculos que permiten el intercambio de saberes y experiencias. Son estas interacciones las que realmente empoderan, las que les facilitan a las mujeres examinar y comparar sus realidades vividas, cuestionar determinados órdenes sociales, fortalecer sus identidades y formular demandas específicas, porque "vuestros silencios no os protegerán” (LORDE, 2003, p. 20). De hecho, cuando el poder que emana de lo erótico está oprimido por factores de género, orientación sexual, raza o clase, la unión y el establecimiento de lazos comunitarios puede contribuir a reducir las diferencias polarizantes. Lorde, por tanto, está hablando de la posibilidad de autorrealización como algo vinculado a la comunidad, de lo erótico como un poder que conecta a las personas consigo mismas y con las demás. Así, frente a los valores de poder y control por los que se rige la epistemología patriarcal moderna, el conocimiento erótico cultiva la conexión empática y el cuidado como ejes desde los cuales ver y experimentar el mundo, lo que proporciona las bases de formas de educación alternativas. Afirma Lorde al respecto: 
Lo erótico actúa de diversas maneras, la primera de las cuales consiste en proporcionar el poder que deriva de compartir profundamente cualquier empeño con otra persona. Compartir el gozo, ya sea físico, emocional, psicológico o intelectual, tiende entre quienes lo comparten un puente que puede ser la base para entender mejor aquello que no se comparte y disminuir el miedo a la diferencia (LORDE, 2003, p. 41).

El saber erótico lleva a la propia Lorde a implicarse, a dar voz a sus sentimientos para que gocen de respeto y puedan servir para tender puentes con los demás, como cuando ella misma comparte su experiencia de padecer cáncer de mama:

Que estas palabras sirvan como incentivo para otras mujeres, para hablar y actuar nuestras experiencias con el cáncer y con otras amenazas de muerte, porque el silencio nunca nos ha traído nada valioso. Más que nada, que estas palabras remarquen las posibilidades de autocuración y la riqueza de la vida, para todas las mujeres (Lorde, 2008, p. 1).

La madre negra interior a la que en ocasiones se refiere Lorde (esa fuente de poder íntimo y recóndito que ha logrado sobrevivir) representa ese otro tipo de conocimiento capaz de reconciliar la razón con la vida. Otro modelo de conocimiento pautado por la sensibilidad ética, el bienestar espiritual, la conexión empática y la conciencia crítica; pautado, en síntesis, por la razón poética de la que habla María Zambrano, la que permite "el florecimiento del delicado saber acerca de las cosas del alma” (2004: 157).

\section{Conclusiones}

Este trabajo responde a la necesidad de reflexionar sobre el vínculo entre las filosofías contemporáneas, en particular las de inspiración feminista, y las preguntas sobre cuestiones de sexualidad, género y poder desde una perspectiva del Sur global. La difusión del pensamiento de mujeres negras, lesbianas, feministas, poetas, madres y guerreras, como se definía la propia Audre Lorde (2008), pueden usarse como herramienta epistémica, política y social para la deconstrucción y la subversión emancipadora de las lógicas colonialistas y patriarcales reproducidas por la colonialidad del saber, lo que permite poner en tela de juicio, entre otros aspectos, la influencia del dualismo cartesiano, del capitalismo y el heteropatriarcado sobre el ser, el saber y el poder, así como abrir la posibilidad de una erotización del saber que acoge y da lugar a otros saberes, a otros modos de pensar, sentir y actuar, es decir, una herramienta que funciona como una epistemología del Sur. 


\section{Referencias}

CASTRO-GÓMEZ, S. Crítica de la razón latinoamericana. Bogotá: Pontificia Universidad Javeriana, 2011.

FOUCAULT, M. Microfísica del poder. Barcelona: Planeta-De Agostini, 1994.

GARAUDY, R. Danzar su vida. México: Conaculta-CENIDID, 2003.

GUEVARA, E. "Discurso al recibir el doctorado honoris causa de la Universidad Central de Las Villas". In: SADER, E., ABOITES, H. y GENTILI, P. (eds.). La reforma universitaria. Desafíos y perspectivas noventa años después. Buenos Aires: CLACSO, 2008.

LANDER, E. (comp.). La colonialidad del saber: eurocentrismo y ciencias sociales. Perspectivas latinoamericanas. Buenos Aires, CLACSO, 2000.

LAURA, R. S. y COTTON, M. Empathetic Education. London: Falmer Press, 1999.

LAURA, R. S. "The epistemology of power and educational ideology". Asian Journal of Science and Technology, vol. 9 (2), 7605-7609, 2018. Disponible en: https://www.journalajst.com/sites/default/files/issues-pdf/5608.pdf [acceso: 1/021/2020].

LEFF, E. "Globalización y sustentabilidad: un encuentro entre la literatura y la filosofía". Cátedra Latinoamericana Julio Cortázar, 2009. Disponible en: http://www.jcortazar.udg.mx/sites/default/files/Enrique\%20Leff.pdf [acceso: 31/01/2020].

LORDE, A. La hermana, la extranjera. Madrid: Horas y Horas, 2003.

LORDE, A. Los diarios del cáncer. Rosario: Hipólita Ediciones, 2008.

MENDOZA, B. "La epistemología del Sur, la colonialidad del género y el feminismo latinoamericano". In: ESPINOSA, Y. Aproximaciones críticas a las prácticas teóricopolíticas del feminismo latinoamericano (ed.). Buenos Aires: En la frontera, 19-36, 2010.

MIGNOLO, W. Historias locales/diseños globales: colonialidad, conocimientos subalternos y pensamiento fronterizo. Madrid: Akal, 2003.

MONTES, A. y BUSSO, H. "Entrevista a Ramón Grosfoguel”. Polis, 18, 2007. Disponible en: http://polis.revues.org/4040 [acceso: 31/01/2020].

QUIJANO, A. "Colonialidad del poder y clasificación social". Journal of World-Systems Research, vol. VI (2), 342-386, 2000.

SANTOS, B. S. Crítica de la razón indolente. Contra el desperdicio de la experiencia. Bilbao: Desclée de Brouwer, 2003.

SANTOS, B. S. El milenio huérfano. Ensayos para una nueva cultura política. Madrid: Trotta/ILSA, 2005.

SANTOS, B. S. Renovar la teoría crítica y reinventar la emancipación social (encuentros en Buenos Aires). Buenos Aires: CLACSO, 2006. 
SANTOS, B. S. Una epistemología del Sur: la reinvención del conocimiento y la emancipación social. México: Siglo XXI. 2009.

SANTOS, B. S. "Epistemologías del Sur". Utopía y praxis latinoamericana, vol. 16 (54), 1739, 2011.

SANTOS, B. S. Justicia entre saberes: epistemologías del Sur contra el epistemicidio. Morata: Madrid, 2017.

SANTOS, B. S. El fin del imperio cognitivo. La afirmación de las epistemologías del Sur. Madrid: Trotta, 2019a.

SANTOS, B. S. y AGUILÓ, A. Aprendizajes globales: descolonizar, desmercantilizar y despatriarcalizar desde las epistemologías del Sur. Barcelona: Icaria, $2019 \mathrm{~b}$.

VIVEROS VIGOYA, M. "Race, Indigeneity, and Gender: Lessons for Global Feminism". In: MESSERSCHMIDT, J. W. et al. (eds.). Gender Reckonings: New Social Theory and Research. New York: New York Press, 2018.

ZAMBRANO, M. "Hacia un saber del alma”. In: MORENO SANZ, J. (ed.). La razón en la sombra. Antología crítica. Madrid: Siruela, 2004, 155-160. 